\title{
Comparative Assessment of Wiper and Conventional Carbide Inserts on Surface Roughness in the Turning of High Strength Steel
}

\author{
Adel Taha Mohamed Abbas ${ }^{1}$ \\ ${ }^{1}$ Department of Mechanical Engineering, College of Engineering, King Saud University, Saudi Arabia \\ Correspondence: Adel Taha Mohamed Abbas, Department of Mechanical Engineering, College of Engineering, \\ King Saud University, Saudi Arabia. E-mail: atabbas1954@yahoo.com
}

\author{
Received: October 10, 2015 Accepted: October 27, 2015 Online Published: October 30, 2015 \\ doi:10.5539/jmsr.v5n1p32 URL: http://dx.doi.org/10.5539/jmsr.v5n1p32
}

\begin{abstract}
Wiper inserts have the characteristics of eliminating many grinding operations and achieving an excellent surface. They also improve component quality and roundness compared with grinding. This paper exposes a performance comparative analysis, involving the criteria of surface roughness $\left(R_{a}, R_{t}\right.$ and $\left.R_{z}\right)$ during high strength steel's turning operation, between the conventional and wiper inserts. The main parameters considered in this study are; the speed of cutting (CS), the feed rate (FR), and the cutting depth (DOC). The test plan was carried-out through (128) test specimens divided into two equal sample groups (A and B), each consists of (64) test specimens. Specimens of group (A) and (B) are tested using wiper and conventional inserts respectively. To apply the required testing conditions, a CNC Turning machine equipped with Sinumeric 840-D, was used. The surface roughness was evaluated using a surface roughness tester (Tesa-rugosurf 90- G). The most important parameters affecting the surface roughness are highlighted. Statistical tests used for this study including the analysis of variance (ANOVA) and the response surface methodology (RSM) are presented. The results show the significance of cutting depth and feed rate in the reduction of surface roughness. The machining conditions producing the optimum roughness of the surface, in the experiment range, were investigated using desirability-function-approach for the optimization of multiple-factors of response. The results showed that the quality of surface derived with the wiper carbide insert has significant improvement in comparison to the conventional carbide insert. The maximum improvement of 3.5 times between the wiper insert and conventional insert was achieved at a surfacing speed of $75 \mathrm{~meter} / \mathrm{min}$ and is limited to 3, 2.5 and 2 times for a surfacing speed of 100, 125 and $150 \mathrm{~meter} / \mathrm{min}$, respectively.
\end{abstract}

Keywords: wiper inserts, surface roughness measurement, turning operation, process parameters

\section{Introduction}

The machining process of hard turning has drawn increased attention in research and development. Hardened steels exhibit many attractive properties, such as wear resistance, high strength, and high thermal stability, and have a variety of uses, including dies, automobiles, bearings, and gears. Due to the industrial importance of hardened steels, there is a need for advanced technologies in the machining of these materials (Srithar, Palanikumar, \& Durgaprasad, 2014), namely, in the development of processes with a higher material removal rate (MRR). Hard turning works on materials by making use of various solid cutting tools. The development of wiper inserts started in recent years with the fabrication of cemented carbide inserts. Wiper inserts can eliminate many of the operations in grinding and achieve excellent surface finish. Wipers also improve the roundness and overall quality of the component in comparison to grinding. The main factor affecting turning operation performance is the feed. It is estimated that the cutting time can be reduced to half when the feed is doubled; consequently, it is possible to achieve twice the number of components within the same time duration (Sandvik, 2014).

There is increased competition in the manufacturing industries to achieve high-quality products and high productivity. Finished products of desired sizes and shapes are conventionally manufactured by turning performed blanks with the aid of cutting tools. During this production, a key requirement is the quality of the surface, as surface roughness can affect fatigue strength, wear rates, assembly tolerance, coefficients of friction, clean-ability, corrosion resistance, and aesthetics (Sahoo, Baral, Rout, \& Routra, 2012). In addition, the manufacturing industry requires higher rates of material removal for feasible mass production while retaining the product quality. Higher removal rates can be obtained by adjusting the process parameters such as cutting speed, cutting depth, and feed rate. 
Higher cutting speeds would require greater power input that could eventually exceed the power capacity of the machine tool. Likewise, increasing other process parameters could result in higher cutting temperatures, which would be harmful to the product, as well as to the tool. It could lead to dimensional inaccuracies via thermal deformation, impact the machined surfaces through built-up edge formations and thermal defects, and impair the movement and sharpness of the tool. Given their pivotal role in the efficiency, effectiveness, and overall economy of manufacturing, it is important to select appropriate process parameters (Sahoo, Baral, Rout, \& Routra, 2012).There are various benefits of hard machining in comparison to the process of grinding. The implementation of the technology requires producing surfaces that meet the requirements of integrity and surface finish. At the same time, the technology should be economically viable. The development of harder work materials has promoted the technology of tool material at a faster rate. The technology has the potential of achieving machining of the materials with reliable performance and higher material removal rate (Suresh, Basavarajappa, Gaitonde, Samuel, \& Davim, 2013). This study aims to compare the surface quality achieved using wiper and conventional carbide inserts in the turning of high-strength steel. This study investigates whether the surface quality derived with the wiper carbide insert exhibits improvement in surface roughness in comparison to the conventional carbide insert.

\section{Literature Review}

Researchers have conducted various investigations into the performance of ceramic tools and cubic boron nitride $(\mathrm{CBN})$ in the machining of hard materials. However, there has been no systematic study describing the statistical effects of turning parameters and other associated conditions. Çaydas (2010) in this study, it was concluded that increasing the tempering temperature resulted in a corresponding decrease in the hardness of the samples. These findings showed that the best surface roughness was achieved when CBN tools were followed by ceramic and then grade carbide tools. Conventionally, the finish machining of hardened steel is accomplished through the process of grinding. In this process, the grinding wheel's shape is a major limitation in its application to geometries of regular workpieces; this is one of the many reasons why finish hard turning is preferred over grinding. Other benefits include reduced setup time and increased metal removal rate. CBN tools are appropriate for hard machining of steels because they are chemically inert to steel (Dureja, Gupta, Sharma, \& Dogra, 2010).

\subsection{Hard Turning and Grinding}

Steel parts are used for carrying critical loads in jet engines and automotive drive trains. These parts are conventionally manufactured by a series of processes, which include costly and time-consuming polishing and grinding. A less costly and efficient method to produce these parts involves precisely forging hot metal into the parts that are net-shaped, followed by hardening and machining via hard turning. The process of hard turning differs from the process of conventional turning mainly in the hardness of the workpiece, the chip formation mechanism involved, and the cutting tool required. The unique feature of hard turning is the direct machining of parts once they are hardened. As a result, the process has lower equipment costs, fewer process steps, shorter setup time, and greater flexibility for part geometry. It is estimated that hard turning can reduce the costs of manufacturing by up to $30 \%$ (Dureja, Gupta, Sharma, \& Dogra, 2010).

Gaitonde et al. (2009a) Hard turning with a ceramic cutting tool has several advantages over the process of grinding. These include no need for a coolant, improved material properties, reduced processing costs, reduced power consumption, and increased productivity. However, the benefits of hard turning do not allow it to fully replace grinding because there is still insufficient data concerning tool wear and surface quality. This paper is an attempt to identify the impacts of machining time and cutting depth on the dimensions of machinability. The experiments were carried out according to full factorial design (FFD). The parametric analysis showed that the CC650 conventional insert was beneficial in reducing the machining force, specific cutting force, and power, while the performance of CC650WG wiper insert was superior with respect to tool wear and surface roughness.

Gaitonde et al. (2011) studied the influence of cutting speed, feed rate, and machining time on machinability aspects. Specifically, the cutting force, surface roughness, and tool wear in AISI D2 cold work tool steel hard turning have been investigated for three different ceramic inserts, namely, CC650, CC650WG, and GC6050WH. A multilayer feed-forward artificial neural network (ANN), trained using error back-propagation training algorithm has been employed for predicting the machinability. The input-output patterns required for the ANN training and testing are obtained from the turning experiments planned through full factorial design. The simulation results demonstrate the effectiveness of ANN models to analyze the effects of cutting conditions as well as to study the performance of conventional and wiper ceramic inserts on machinability. 
Gaitonde et al. (2009b) established the relationships between the cutting conditions (cutting speed, feed rate, and machining time) and machinability aspects (machining force, power, specific cutting force, surface roughness, and tool wear). The surface response methodology-based mathematical models are proposed for modeling and analyzing the effects of process parameters on machinability during turning of high chromium AISI D2 cold work tool steel using CC650WG wiper ceramic inserts. The experiments have been planned as per full factorial design. From the parametric analysis, it is revealed that the power increases with the rising of the feed rate, while the specific cutting force decreases, whereas the requirement of machining force is low at small values of feed rate and machining time. The surface response analysis also indicates that the surface roughness can be reduced at lower values of feed rates and machining time with higher values of cutting speeds, while the maximum tool wear occurs at a cutting speed of $150 \mathrm{~m} / \mathrm{min}$ for all values of feed rates.

Quiza, Figueira, and Davim (2008) carried out an experimental investigation using ceramic cutting tools, composed approximately of $\mathrm{Al} 2 \mathrm{O} 3(70 \%)$ and $\mathrm{TiC}(30 \%)$, on cold work tool steel D2 (AISI) heat treated to a hardness of $60 \mathrm{HRC}$. Two models were adjusted to predict tool wear for different values of cutting speed, feed and time. One of them is based on statistical regression, and the other is based on a multilayer perceptron neural network. Parameters of the design and the training process, for the neural network, have been optimized using the Taguchi method. Outcomes from the two models were analyzed and compared. The neural network model has shown better capability to make accurate predictions of tool wear under the conditions studied.

Davim et al. (Davim \& Figueira, 2007; Davim, 2011) considered the influence of the wiper inserts when compared with conventional inserts on the machinability parameters (cutting forces, surface roughness, and tool wear) obtained in hard turning of AISI D2 hardened steel. A plan of experiments was established considering hard turning with predetermined cutting parameters. An analysis of variance (ANOVA) was performed to investigate the machinability parameters using conventional and wiper inserts. With wiper ceramics inserts, machined surfaces with $R a<0.8 \mu \mathrm{m}$ were achievable. Consequently, surface qualities (dimensional accuracy) in a workpiece of mechanical precision, IT $<7$, are possible.

\subsection{Impact of the Radius of the Cutting Edge}

Fulemova and Janda (2014) discussed the impact of the radius of the cutting edge and the preparation of the edge on the tool life, machined surface's roughness, and cutting forces. The preparation of a cutting edge was accomplished by using a wiper geometry for the inserts. The inserts were used to machine a steam turbine casing of steam turbine during the process of dividing planes. The cutting inserts were fabricated by grinding, dragfinishing and laser ablation. The radii of the edges of the drag-finished tools were 5, 10 and $15 \mu \mathrm{m}$; laser-finished tools had an edge radius of $5 \mu \mathrm{m}$. The workpiece material was a dual phase ferrite-martensite steel, consisting of $1 \%$ chromium and $9 \%$ molybdenum. Submicron sintered carbide was used as the cutting insert material, and in the milling cutter, only one cutting insert was present.

\subsection{Machining Technology}

Fulemova and Janda (2014) looked into the surface roughness of the workpiece, which the authors considered to be a crucial factor in the technology of machining. Wiper inserts have been gaining popularity due to their significance in cutting tools and have been utilizing for the past several years. This research examines the impact of the wiper inserts surface roughness in comparison to conventional inserts. Experiments were conducted for AISI 1045 carbon steel, due to the steel's importance in manufacturing industry. Different amplitude parameters were used to quantify the roughness of the surface (Ra, Rz, Rq, Rt). Machined surfaces with Ra less than $0.8 \mu \mathrm{m}$ (micron) were achieved at a high feed rate and with the use of wiper inserts. Thus, it is possible to obtain a precise and highquality workpiece surface without cylindrical grinding.

\subsection{Predictive Model}

Ozel, Karpat, Figueira, and Davim (2007) the design of the tool nose impacts the productivity of and surface finishing from hard turning. The setup utilizes neural network modeling as a prediction tool. Predictions were made for tool flank wear and surface roughness. In addition, the arrangement also employed multiple regression models to provide the predictions. The results from experiment showed that surface roughness values $R \mathrm{a}$ as low as $0.18-0.20 \mu \mathrm{m}$ were attainable using wiper inserts. Analysis of the tool flank wear attained a tool life criterion value of $\mathrm{VBC}=0.15 \mathrm{~mm}$ due to the elevated temperatures at high cutting speeds at up to 15 minutes of cutting time. The comparison was made with experimental data that were non-training. The findings indicated that the neural network models were appropriate for predicting the surface roughness and tool wear patterns for a range of cutting conditions. 


\subsection{Grinding Alternative}

Guddat, M'Saoubi, Alm, and Meyer (2011) Due to its high productivity and flexibility and no need for coolants, hard turning is currently considered (in the finishing of hardened steel workpieces) to be an alternative to grinding. The use of wiper PCBN inserts results in the reduction of surface roughness compared to the use of conventional inserts for machining experiments at enhanced feed rates. Although these are the well-known benefits, the impact of wiper PCBN inserts on the surface integrity during hard turning has not been discussed in detail in the literature. This study aims to investigate the impact of wiper PCBN inserts on the finishing cutting forces and surface integrity of hardened AISI 52100 (100Cr6) (58-62 HRC). A statistical model was developed to predict the surface roughness values and cutting forces for a range of cutting parameters. The assessment of subsurface and surface integrity revealed that, in comparison to conventional geometrical inserts, the implementation of $\mathrm{PBCN}$ wiper inserts led to higher compressive residual stresses and marked improvement in the surface roughness.

\subsection{Desirability Function Approach}

Research from Elbah, Yallese, Aouici, Mabrouki, and Rigal (2013) compared the surface roughness (Ra, Rt, Rz) produced using wiper and conventional inserts. The comparison was made for the hard turning of AISI 4140 hardened steel (60 HRC), and the experiments were planned using a Taguchi (L27) orthogonal array. The analysis of variance (ANOVA) and response surface methodology (RSM) were employed to check the validity of the quadratic regression model. The tests were also used to identify the significant parameter impacting the roughness of the surface. The findings showed that the cutting depth and rate of feed significant impacted the roughness of the surface. The best machining conditions for producing the optimum surface roughness in the ranges considered in these experiments were determined by using desirability function. The findings demonstrated that the quality of the surface finished with the ceramic wiper inserts was radically improved compared to the quality from the conventional ceramic inserts by a factor of 2.5 . The measurements of roughness indicated a dependence on CC6050WH tool wear. However, although the wear reached up to the permitted flank wear value of $0.3 \mathrm{~mm}$ the roughness Ra was always less than $0.9 \mu \mathrm{m}$.

\subsection{Green Manufacturing}

According to Grzesik and Wanat (2006), much progress has already made in the domain of green manufacturing, including hard and dry (often high-speed) machining technologies. For example, the need for increased productivity has given rise to the wider application of PCBN and ceramic tools with special multi-radii/wiper geometries. This study mentions some key features in the surface roughness developed in the turning of hardened low-chromium alloy steel. The study used mixed alumina-titanium carbon (TiC) ceramic cutting tools, which were equipped with both wiper and conventional inserts. The key geometrical characteristics of the surfaces obtained from both tools were extracted using leading two-dimensional (2D) parameters of the surface roughness and 3D visualization, which provided comprehensive surface topography and prediction of the properties of service. The findings indicated that for equivalent rates of feed, i.e., $0.2 \mathrm{~mm} / \mathrm{rev}$ for wiper tools and $0.1 \mathrm{~mm} / \mathrm{rev}$ for conventional tools, the resultant surfaces had equivalent 3D roughness height parameters and comparable figures of skew/kurtosis. For pre-determined parameters of cutting, surfaces finished with wipers consisted of blunt peaks with clearly smaller slopes, compared with surfaces finished with conventional inserts, which promoted in superior bearing properties. Only minor changes in Ra were noted among the 15-minute machining trials.

\subsection{Updated Technique of Optimization}

Paiva et al. (2012) describes an experimental study using AISI 52100 hardened steel employing Multivariate Robust Parameter Design (MRPD). The hardened steel was turned with wiper inserts made from mixed ceramic (Al2O3+TiC) and coated with TiN. The key features of MRPD is that it considers both noise (zi) and controllable (xi) variables in the hard turning process to determine the parameter values that would minimize the response distance (yi) from the respective targets (Ti) while maintaining the minimum variance value for each variable. By using a crossed array, a response surface design was submitted to the impact of four cases developed with a 22 full factorial design of two noise factors - tool flank wear (Z2) and workpiece hardness decreasing (Z1). The response survey design was consisted of the feed rate (f), cutting speed (Vc), and cutting depth (d). This arrangement of the experiment enabled the calculation of the variances, means and mean square errors (MSE) for the five surface roughness parameters ( $\mathrm{Ra}, \mathrm{Ry}, \mathrm{Rz}, \mathrm{Rq}$, and $\mathrm{Rt}$ ). As there was a positive correlation in these responses, to apply and extrapolate the information, the study used Principal Component Analysis (PCA). The researcher used the multivariate mean square error (MMSE) as the criterion for optimization to find a robust solution. The experimental and theoretical results were confirmed and found to be convergent. for $\mathrm{f}=0.191 \mathrm{~mm} / \mathrm{rev}, \mathrm{Vc}=199.9$ meter $/ \mathrm{min}$, and $\mathrm{d}=0.190 \mathrm{~mm}$, the five surface roughness parameters and the variances were reduced. The results were better than the results obtained with individual optimization. 


\subsection{Milling Cutter Systems}

de Souza Jr, Sales, Santos, and Machado (2005) used two face milling cutter systems encountered in the shop floor under cutting condition in the high-speed cutting of gray cast iron. The first system 'A' had 24 Si3N4 inserts with square wiper edges. The second system 'B' was a mixed tool material system with 24 wiper inserts, 20 of which were Si3N4 interspersed with 4 inserts of PCBN. The constants included speed of cutting (Vc), feed rate per tooth (fz), and depth of cut (doc). The parameters of surface roughness (Rt and Ra) and waviness (Wt), burr formation (length of the burr, h), and tool life (based on flank wear, VBB max) were used to compare the two systems. The performance of system B was better than the performance of system A based on all parameters, although only the end-of-life criterion on the basis of Rt parameter has been marked.

\subsection{Energy-dispersive X-ray (EDX) Micro-analysis}

Grzesik (2009) analyzed the mechanisms of wear from using mixed ceramic inserts on 60-HRC steel (equivalent to DIN $41 \mathrm{Cr} 4$ or AISI 5140) specimens in hard and dry finish turning operations. Various tests were executed under different rater of feed, a small cutting depth of $0.2 \mathrm{~mm}$, and a constant speed of cutting of $100 \mathrm{~m} / \mathrm{min}$. Light optical microscopy (LOM), back-scattered electron (BSE) techniques, and scanning electron microscopy (SEM) were carried out to analyze the morphological characteristics of worn surfaces developed under different mechanisms of wear. Moreover, the elemental compositions of the products of wear were determined by energydispersive X-ray (EDX) micro-analysis (also known as energy-dispersive X-ray spectroscopy (EDS)). Thus, the microstructure and microscopic dimensions of tool wear were considered. In summary, the wear mechanisms analyzed in these tests included fracture, abrasion, BUE, plastic flow and transferred layers, and tribochemical impacts. Signatures of different wear mechanisms appeared depending on the thermal and mechanical conditions produced in the contacted areas. Particularly, two forms of material transfer with varying morphologies occurring at the rake-chip interface were especially pronounced.

\subsection{Wide use of wiper inserts}

Today, wiper inserts are the top choice for a wide variety of application to ensure maximum productivity and versatility. With productive wiper inserts there are alternative also available when cutting conditions change. Wiper inserts enable improved machining economy, excellent surface finishes, the elimination of expensive grinding operations, and undisturbed production and require less supervision and reduced inventory. Figure 1 shows the edge preparation for different wiper inserts and conventional finishing inserts (Sandvik, 2014).
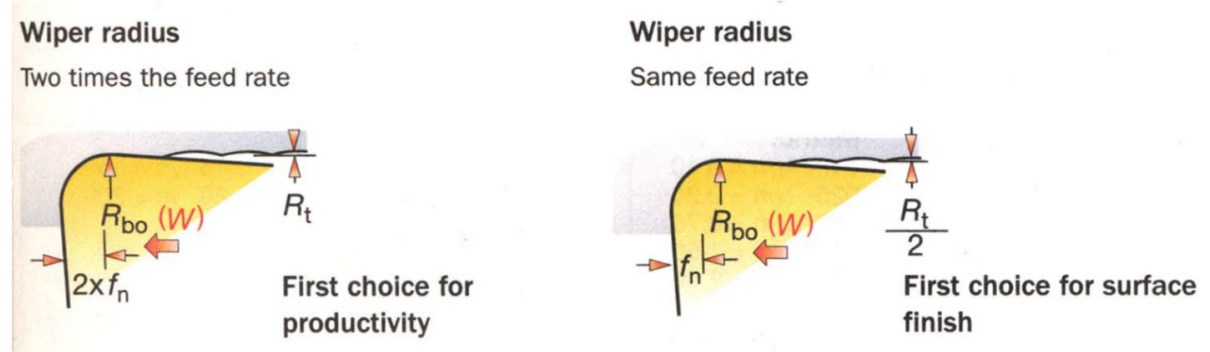

Figure 1. Edge preparation for different wiper inserts and regular finishing insert

\section{Materials and Methods}

The chemical compositions of the high-strength steel material considered here is shown in Table 1. The material was austenitized at $900^{\circ} \mathrm{C}$ for $5 \mathrm{hr}$., air-cooled, heated at $880^{\circ} \mathrm{C}$ for $5 \mathrm{hr}$., quenched in oil, tempered at 590 to $600^{\circ} \mathrm{C}$ for $8 \mathrm{hr}$., and finally air-cooled once more. The hardness was HV 400 to 420.

Table 1. Chemical composition for high strength steel material

\begin{tabular}{llllllllll}
\hline Range & $\mathrm{C}$ & $\mathrm{Si}$ & $\mathrm{Mn}$ & $\mathrm{Ni}$ & $\mathrm{Cr}$ & $\mathrm{Mo}$ & $\mathrm{V}$ & $\mathrm{S}$ & $P$ \\
\hline From & 0.32 & $<0.25$ & 0.55 & 2.5 & 0.9 & 0.45 & 0.09 & $\leq 0.004$ & $\leq 0.008$ \\
To & 0.36 & & 0.65 & 3.2 & 1.1 & 0.55 & 0.12 & & \\
\hline
\end{tabular}


The test specimens were made with an initial diameter of $50 \mathrm{~mm}$ and length of $100 \mathrm{~mm}$, with $40 \mathrm{~mm}$ of the length used for chuck clamping, $10 \mathrm{~mm}$ for clearance grooving, and the remaining $50 \mathrm{~mm}$ for testing. At the other end of test specimen, a standard conical center was created for supporting the center of the tail stock.

An EMCO Concept Turn 45 CNC lathe equipped with Sinumeric 840D was used to conduct the experiments. Wiper and conventional carbide inserts were clamped into the tool holders. The specifications for the wiper and conventional inserts were DCMX11T304-WF, DCMT11T304-PF, respectively, while the tool holders were the same, SDJCL 2020K11. The clearance angle, cutting edge angle and nose radius were maintained at $7^{\circ}, 55^{\circ}$ and $0.4 \mathrm{~mm}$, respectively. All the experiments were conducted in wet conditions. The surface roughness was measured and reported for a length $50 \mathrm{~mm}$ and evaluated using a surface roughness tester Tessa. All cutting parameters were controlled using a CNC part program. Figure 2 shows the test rig for machining the test specimens and measuring the surface roughness.
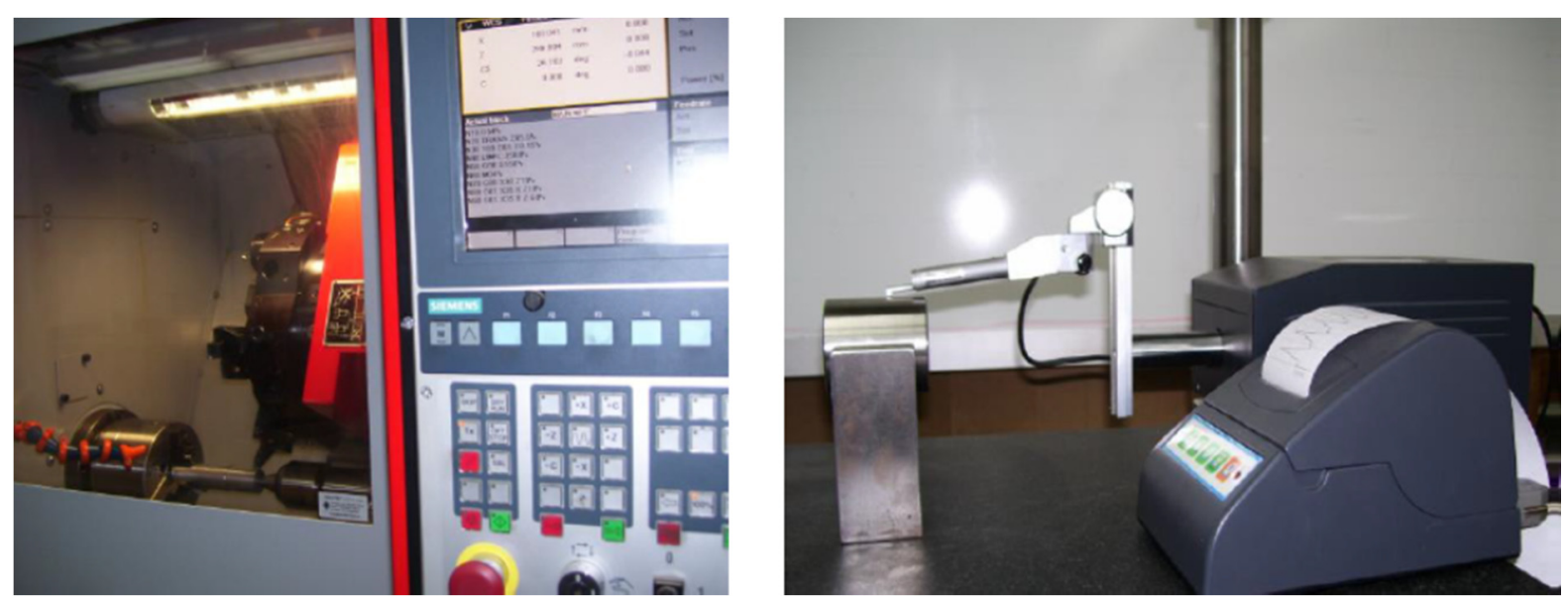

Figure 2. Test Rig for machining the workpieces and measuring the surface roughness

The test plan was carried out using (128) test specimens. The specimens were divided into two equal divisions (A and B), each division consisting of (64) test specimens and tested using wiper inserts and conventional inserts, respectively. Each division was further divided into 16 groups, where each of the four groups was machined at a fixed speed. Groups 1-4, 5-8, 9-12 and 13-16 were processed at speeds of 75 meter/min, $100 \mathrm{~meter} / \mathrm{min}, 125$ meter/min and $150 \mathrm{~meter} / \mathrm{min}$, respectively. Each sample in each group was machined to a different cutting depth $(0.1,0.15,0.20$ and $0.25 \mathrm{~mm})$, and each depth was processed at a different feed rate $(0.05,0.1,0.15$ and 0.20 $\mathrm{mm} / \mathrm{rev}$, respectively).The cutting parameters and surface roughness $\left(R_{a}, R_{t}\right.$ and $\left.R_{z}\right)$ for Groups 1-4, 5-8, 9-12 and 13-16 are listed in Appendix $A$, where $R_{a}=$ arithmetic mean roughness $(\mu \mathrm{m}), R_{t}=$ total roughness $(\mu \mathrm{m}), R_{z}=$ mean depth of profile $(\mu \mathrm{m})$.

\section{Results and Discussion}

\subsection{Analysis of Variance}

The processes parameters considered here are; speed, feed and depth of cut while the response variable is the surface roughness $\left(R_{a}, R_{t}\right.$ and $\left.R_{z}\right)$. The results of the study were entered into SPSS for analysis of variance. Division (A) samples was finished using wiper inserts and division (B) samples were finished with conventional inserts. There was a total 16 groups in each division: groups 1 to 4 were machined at $75 \mathrm{~meter} / \mathrm{min}$, groups 5 to 8 at 100 meter/min, groups 9 to 12 at $125 \mathrm{~meter} / \mathrm{min}$, and groups 13 to 16 at $150 \mathrm{~meter} / \mathrm{min}$.

The statistical analysis was conducted to determine if there were significant differences in the mean values in division $\mathrm{A}$ and division $\mathrm{B}$ for the different machining speeds. The results are as shown in Table $2 \mathrm{a}$ and $\mathrm{b}$.

For the mean Ra in division A, the ANOVA analysis calculated a significance level of 0.039 , which is below 0.05 . Hence, there is a statistically significant difference in the mean values of Ra between the different machining speeds with the wiper insert. The mean value of Ra increased for machining speeds up to $125 \mathrm{~meter} / \mathrm{min}$, after which it began to decrease, as shown in Table $3 a$ and $b$. 
Table 2a. Descriptive Ra for wiper insert

\begin{tabular}{lllrrrrrr}
\hline & $\mathrm{N}$ & Mean & Std. Deviation & Std. Error & \multicolumn{2}{c}{ 95\% Confidence Interval for Mean } & Minimum & Maximum \\
& & & & \multicolumn{2}{c}{ Lower Bound } & Upper Bound & \\
\hline 75 & 16 & .41394 & .192303 & .048076 & .31147 & .51641 & .129 & .687 \\
100 & 16 & .44569 & .156611 & .039153 & .36224 & .52914 & .235 & .660 \\
125 & 16 & .56438 & .151701 & .037925 & .48354 & .64521 & .326 & .786 \\
150 & 16 & .54388 & .177148 & .044287 & .44948 & .63827 & .311 & .788 \\
Total & 64 & .49197 & .178050 & .022256 & .44749 & .53644 & .129 & .788 \\
\hline
\end{tabular}

Table 2b. ANOVA Ra for wiper insert

\begin{tabular}{lrrrrr}
\hline & Sum of Squares & df & Mean Square & F & \multicolumn{1}{c}{ Sig. } \\
\hline Between Groups & .259 & 3 & .086 & 2.976 & .039 \\
Within Groups & 1.739 & 60 & .029 & & \\
Total & 1.997 & 63 & & & \\
\hline
\end{tabular}

Table 3a. Descriptive Ra for conventional insert

\begin{tabular}{|c|c|c|c|c|c|c|c|c|}
\hline & \multirow[t]{2}{*}{$\mathrm{N}$} & \multirow[t]{2}{*}{ Mean } & \multirow[t]{2}{*}{$\begin{array}{c}\text { Std. } \\
\text { Deviation }\end{array}$} & \multirow[t]{2}{*}{$\begin{array}{l}\text { Std. } \\
\text { Error }\end{array}$} & \multicolumn{2}{|c|}{$\begin{array}{l}\text { 95\% Confidence Interval for } \\
\text { Mean }\end{array}$} & \multirow[t]{2}{*}{ Minimum } & \multirow[t]{2}{*}{ Maximum } \\
\hline & & & & & Lower Bound & Upper Bound & & \\
\hline 75 & 16 & 1.45150 & .676214 & .169054 & 1.09117 & 1.81183 & .454 & 2.402 \\
\hline 100 & 16 & 1.36769 & .474170 & .118543 & 1.11502 & 1.62035 & .746 & 1.990 \\
\hline 125 & 16 & 1.41869 & .378276 & .094569 & 1.21712 & 1.62026 & .817 & 1.960 \\
\hline 150 & 16 & 1.10838 & .360905 & .090226 & .91606 & 1.30069 & .629 & 1.645 \\
\hline Total & 64 & 1.33656 & .496010 & .062001 & 1.21266 & 1.46046 & .454 & 2.402 \\
\hline
\end{tabular}

Table 3b. ANOVA Ra for conventional insert

\begin{tabular}{lrrrrr}
\hline & Sum of Squares & df & Mean Square & F & Sig. \\
\hline Between Groups & 1.168 & 3 & .389 & 1.630 & .192 \\
Within Groups & 14.332 & 60 & .239 & & \\
Total & 15.500 & 63 & & & \\
\hline
\end{tabular}

For the mean Ra in division B, the ANOVA analysis calculated a significance level of 0.192, which is not below 0.05 . Hence, there was no statistically significant difference in the mean values of Ra among the different machining speeds with the conventional insert, as shown in Table $4 \mathrm{a}$ and $\mathrm{b}$.

Table 4a. Descriptive Rz for wiper insert

\begin{tabular}{|c|c|c|c|c|c|c|c|c|}
\hline & \multirow[t]{2}{*}{$\mathrm{N}$} & \multirow[t]{2}{*}{ Mean } & \multirow[t]{2}{*}{$\begin{array}{c}\text { Std. } \\
\text { Deviation }\end{array}$} & \multirow[t]{2}{*}{$\begin{array}{l}\text { Std. } \\
\text { Error }\end{array}$} & \multicolumn{2}{|c|}{$\begin{array}{l}\text { 95\% Confidence Interval for } \\
\text { Mean }\end{array}$} & \multirow[t]{2}{*}{ Minimum } & \multirow[t]{2}{*}{ Maximum } \\
\hline & & & & & Lower Bound & Upper Bound & & \\
\hline 75 & 16 & 1.80800 & .865630 & .216407 & 1.34674 & 2.26926 & .639 & 3.068 \\
\hline 100 & 16 & 2.35163 & .801152 & .200288 & 1.92472 & 2.77853 & 1.053 & 3.531 \\
\hline 125 & 16 & 3.22644 & .609059 & .152265 & 2.90189 & 3.55098 & 2.173 & 4.036 \\
\hline 150 & 16 & 3.09925 & .475806 & .118952 & 2.84571 & 3.35279 & 2.386 & 3.909 \\
\hline Total & 64 & 2.62133 & .900516 & .112564 & 2.39639 & 2.84627 & .639 & 4.036 \\
\hline
\end{tabular}


Table 4b. ANOVA Rz for wiper insert

\begin{tabular}{lrrrrr}
\hline & Sum of Squares & df & Mean Square & F & Sig. \\
\hline Between Groups & 21.261 & 3 & 7.087 & 14.256 & .000 \\
Within Groups & 29.828 & 60 & .497 & & \\
Total & 51.089 & 63 & & & \\
\hline
\end{tabular}

For the mean Rz in division A, the output of the ANOVA analysis yielded a significance level less than 0.0001 . Hence, there was a statistically significant difference in the mean values of Rz between the different machining speeds with the wiper insert. The mean values of Rz increased with machining speeds up to $125 \mathrm{~meter} / \mathrm{min}$, after which it began to decrease, as shown in Table 5a and $\mathrm{b}$.

Table 5a. Descriptive Rz for conventional insert

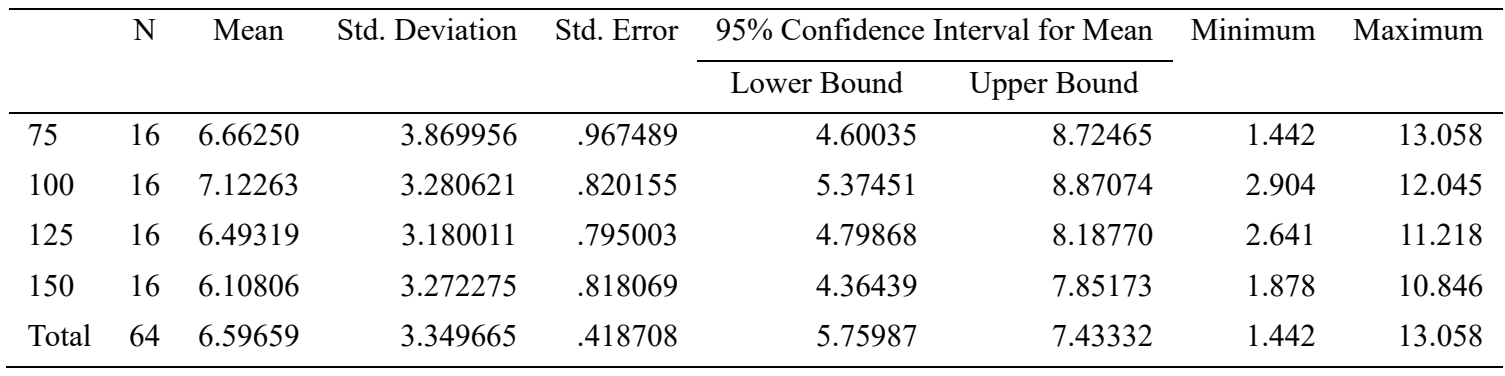

Table 5b. ANOVA Rz conventional insert

\begin{tabular}{lrrrcc}
\hline & Sum of Squares & df & Mean Square & F & Sig. \\
\hline Between Groups & 8.487 & 3 & 2.829 & .243 & .866 \\
Within Groups & 698.389 & 60 & 11.640 & & \\
Total & 706.876 & 63 & & & \\
\hline
\end{tabular}

For the mean Rz in division B, the output of the ANOVA analysis yielded a significance level of 0.866 . Therefore, there was no statistically significant difference in the mean values of Rz between the different machining speeds with the conventional inserts, as shown in Table $6 a$ and $b$.

Table 6a. Descriptive Rt for wiper insert

\begin{tabular}{|c|c|c|c|c|c|c|c|c|}
\hline & \multirow[t]{2}{*}{$\mathrm{N}$} & \multirow[t]{2}{*}{ Mean } & \multirow[t]{2}{*}{$\begin{array}{c}\text { Std. } \\
\text { Deviation }\end{array}$} & \multirow[t]{2}{*}{$\begin{array}{l}\text { Std. } \\
\text { Error }\end{array}$} & \multicolumn{2}{|c|}{$\begin{array}{l}\text { 95\% Confidence Interval for } \\
\text { Mean }\end{array}$} & \multirow[t]{2}{*}{ Minimum } & \multirow[t]{2}{*}{ Maximum } \\
\hline & & & & & Lower Bound & Upper Bound & & \\
\hline 75 & 16 & 1.90013 & .873654 & .218414 & 1.43459 & 2.36566 & .664 & 3.193 \\
\hline 100 & 16 & 2.51056 & .830200 & .207550 & 2.06818 & 2.95294 & 1.114 & 3.655 \\
\hline 125 & 16 & 3.58206 & .536010 & .134002 & 3.29644 & 3.86768 & 2.696 & 4.269 \\
\hline 150 & 16 & 3.48344 & .464557 & .116139 & 3.23589 & 3.73098 & 2.658 & 4.163 \\
\hline Total & 64 & 2.86905 & .980649 & .122581 & 2.62409 & 3.11401 & .664 & 4.269 \\
\hline
\end{tabular}

Table 6b. ANOVA Rt for wiper insert

\begin{tabular}{lrrrrr}
\hline & Sum of Squares & df & Mean Square & F & Sig. \\
\hline Between Groups & 31.251 & 3 & 10.417 & 21.307 & .000 \\
Within Groups & 29.334 & 60 & .489 & & \\
Total & 60.585 & 63 & & & \\
\hline
\end{tabular}


For the mean Rt in division A, the ANOVA analysis calculated a significance level less than 0.0001 . Therefore, there was a statistically significant difference in the mean values of Rt between the different machining speeds with the wiper insert. The mean values of Rt increased with the machining speed up to $125 \mathrm{~meter} / \mathrm{min}$, after which it began to decrease, as shown in Table $7 \mathrm{a}$ and $\mathrm{b}$.

Table 7a. Descriptive Rt for conventional insert

\begin{tabular}{lllrrrrrr}
\hline & $\mathrm{N}$ & Mean & Std. Deviation & Std. Error & \multicolumn{2}{c}{$95 \%$ Confidence Interval for Mean } & Minimum & Maximum \\
& & & & & Lower Bound & Upper Bound & & \\
\hline 75 & 16 & 6.87019 & 3.912362 & .978090 & 4.78544 & 8.95494 & 1.596 & 13.153 \\
100 & 16 & 7.32213 & 3.315463 & .828866 & 5.55544 & 9.08881 & 3.074 & 12.145 \\
125 & 16 & 6.72962 & 3.213627 & .803407 & 5.01720 & 8.44205 & 2.760 & 11.479 \\
150 & 16 & 6.36525 & 3.345241 & .836310 & 4.58270 & 8.14780 & 2.074 & 11.191 \\
Total & 64 & 6.82180 & 3.391790 & .423974 & 5.97455 & 7.66904 & 1.596 & 13.153 \\
\hline
\end{tabular}

Table 7b. ANOVA Rt for conventional insert

\begin{tabular}{lrrrrr}
\hline & Sum of Squares & df & Mean Square & F & Sig. \\
\hline Between Groups & 7.514 & 3 & 2.505 & .210 & .889 \\
Within Groups & 717.254 & 60 & 11.954 & & \\
Total & 724.767 & 63 & & & \\
\hline
\end{tabular}

For the mean Rt in division B, the output of the ANOVA analysis yielded a significance level of 0.889 . Hence, there was no statistically significant difference in the mean values of Rt between the different machining speeds with the conventional insert.

Overall, the results of the study showed significant differences in the mean values in the wiper insert cases; however, there were no significant differences in the conventional insert cases. At $75 \mathrm{~meter} / \mathrm{min}$, the improvement in the wiper insert groups was 3.5 compared to conventional inserts. At $100 \mathrm{~meter} / \mathrm{min}$, the difference between the two insert cases was 3.0. At $125 \mathrm{~meter} / \mathrm{min}$, the improvement was a value/factor of 2.5 between the two cases. At $150 \mathrm{~meter} / \mathrm{min}$, the improvement factor/value was 2.0. From the results, it is evident that the level of improvement decreased with the increase in machining speed.

\subsection{Response Surface Methodology}

The response surface methodology was used to determine the relationship between the required response and the independent parameters of the process. There were six steps involved. The quadratic model for the roughness of the surface is given as follows:

$$
Y=b_{0}+\sum_{i=1}^{k} b_{i} X_{i}+\sum_{i, j}^{k} b_{i j} X_{i} X_{j}+\sum_{i=1}^{k} b_{i i} X_{i}^{2}
$$

In the above equation, the desired response is denoted by $\mathrm{Y}, \mathrm{Xi}$ is the coded variable related to the cutting parameters, $b_{\mathrm{o}}$ is a constant, and bj, bii, and bij are coefficients. Figure $3 \mathrm{a}$ and $3 \mathrm{~b}$ show the impact of feed rate and cutting depth on the roughness of the surface at 75 meter/min using the wiper insert (DCMX11T304-WF) and the conventional insert (DCMT11T304-PF), respectively. The measurements indicated that the tool wear was heavily dependent on DCMX11T304-WF, as depicted by the direction of the graph.

Figure $4 \mathrm{a}$ and $\mathrm{b}$ show the impact of feed rate and cutting depth on the mean depth of profile at $75 \mathrm{~meter} / \mathrm{min}$ using the wiper insert (DCMX11T304-WF) and the conventional insert (DCMT11T304-PF), respectively. The measurements indicate that the tool wear was heavily dependent on DCMX11T304-WF as depicted by the direction of the graph.

Figure 5 shows the values of Ra, Rt, and Rz for the wiper insert cases at the speed of 75 meter/min. 


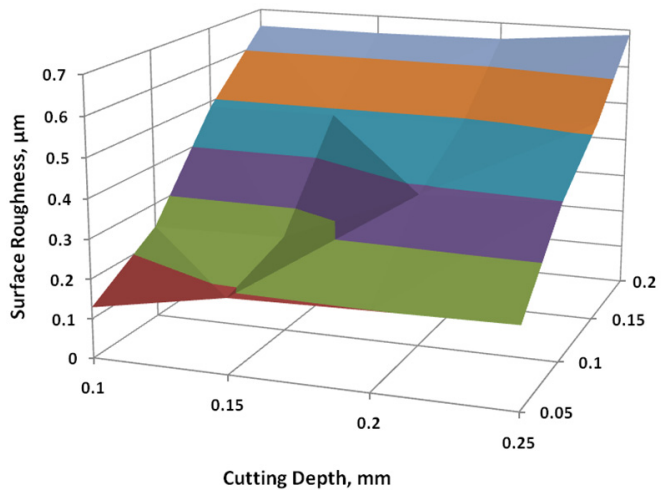

Figure 3a. Impact of feed rate and cutting depth on the roughness of the surface for machining speed of $75 \mathrm{~meter} / \mathrm{min}$ (Wiper Insert)

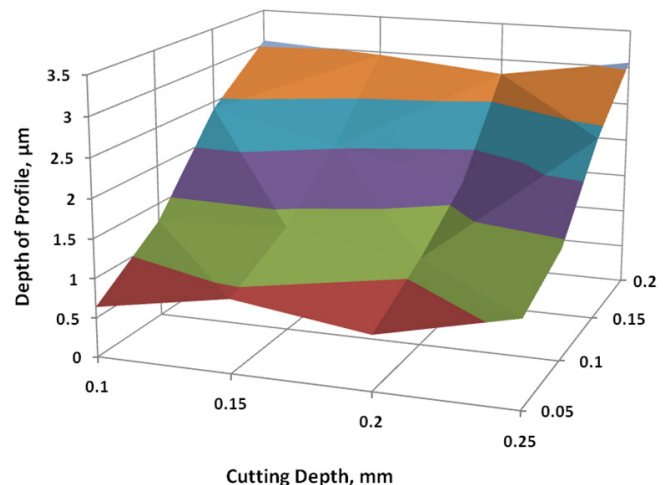

Figure 4a. Impact of feed rate and cutting depth on the mean depth of profile for machining speed of 75 meter/min (Wiper Insert)

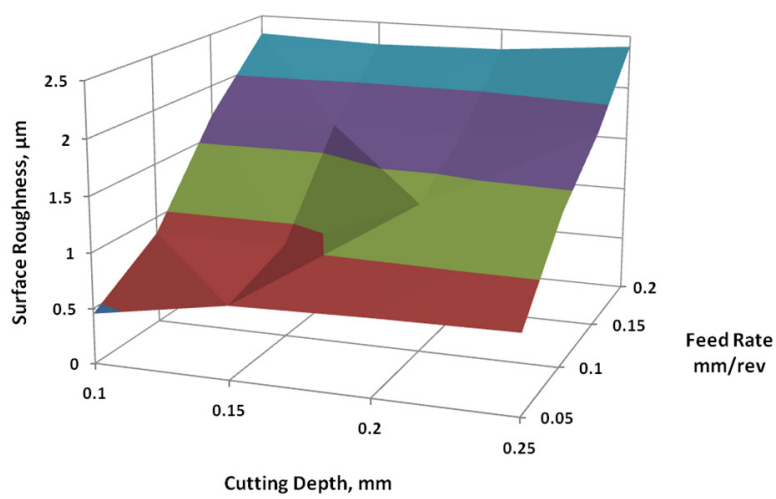

Figure 3b. Impact of feed rate and cutting depth on the roughness of the surface for machining speed of 75 meter/min (Conventional Insert)

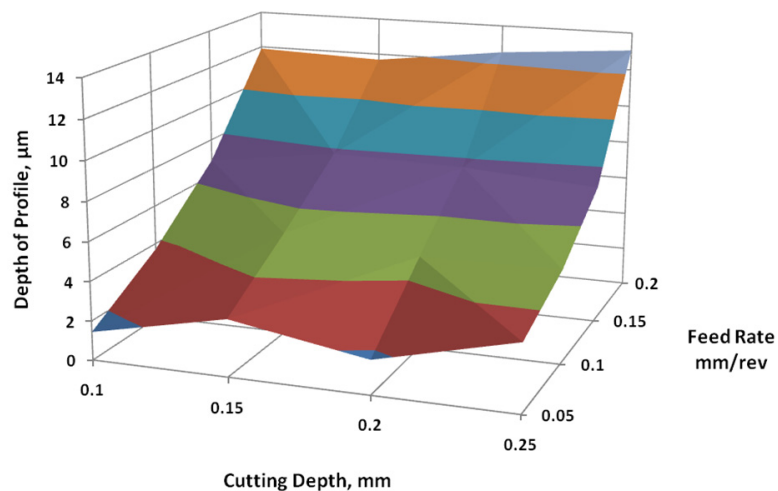

Figure 4b. Impact of feed rate and cutting depth on the mean depth of profile for machining speed of 75 meter/min (Conventional Insert)

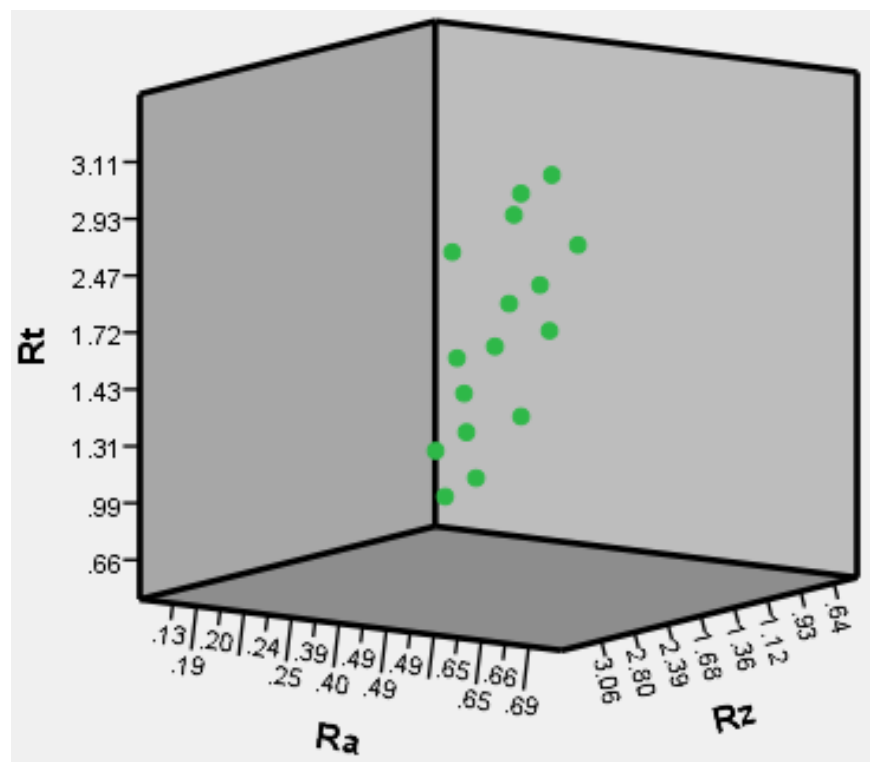

Figure 5. Values of Ra, Rt, and Rz for wiper insert for machining speed of 75 meter/min 


\subsection{Comparison with Literature Review}

The review of the literature has highlighted the benefits of hard turning over the process of grinding. Wiper inserts were presented to reduce many of the operations of grinding and to achieve excellent surface finishes. Wiper inserts were determined to be superior with respect to tool wear and surface roughness. The findings of this study provided further support for the results of earlier studies (Davim \& Figueira, 2007; Davim, 2011). The statistical analysis showed that there were significant differences in the values of $\mathrm{Ra}, \mathrm{Rz}$, and $\mathrm{Rt}$ when using wiper inserts at different machining speeds. The mean values of $\mathrm{Ra}, \mathrm{Rz}$, and $\mathrm{Rt}$ increased with the increase in machining speed up to a certain level, beyond which the mean value decreased.

\section{Conclusions}

This study involved a comparative analysis of the effects of wiper inserts and conventional inserts on surface roughness in hard turning. The experiments were performed on 128 test specimens. The arithmetic mean roughness, the total roughness, and the mean depth of profile were calculated, and analyses of variance and the surface response were performed. The optimal machining conditions to yield the best surface characteristics for the given experimental range were investigated using a desirability function approach. The results indicated that the quality of the surface obtained from a wiper carbide insert was significantly improved in comparison to that from a conventional carbide insert. The maximum improvement of 3.5 times between the wiper insert and conventional insert was achieved at a surfacing speed of $75 \mathrm{~meter} / \mathrm{min}$ and is limited to $3,2.5$ and 2 times for a surfacing speed of 100,125 and $150 \mathrm{~meter} / \mathrm{min}$, respectively. These results can be considered as useful guide to the manufacturing engineers as they have great impact on the quality of the final products.

\section{References}

Çaydas, U. (2010). Machinability evaluation in hard turning of AISI 4340 steel with different cutting tools using statistical techniques. Proceedings of the Institution of Mechanical Engineers, 224, 1043-1055.

Correia, A. E., \& Davim, J. P. (2011). Surface roughness measurement in turning carbon steel AISI 1045 using wiper inserts. Measurement, 44(5), 1000-1005.

Davim, J. P. (Ed.). (2011). Machining of hard materials. Springer Science \& Business Media.

Davim, J. P., \& Figueira, L. (2007). Comparative evaluation of conventional and wiper ceramic tools on cutting forces, surface roughness, and tool wear in hard turning AISI D2 steel. Proceedings of the Institution of Mechanical Engineers, Part B: Journal of Engineering Manufacture, 221(4), 625-633.

de Souza Jr, A. M., Sales, W. F., Santos, S. C., \& Machado, A. R. (2005). Performance of single Si 3 N 4 and mixed Si $3 \mathrm{~N} 4+$ PCBN wiper cutting tools applied to high speed face milling of cast iron. International Journal of Machine Tools and Manufacture, 45(3), 335-344.

Dureja, J. S., Gupta, V. K., Sharma, V. S., \& Dogra, M. (2010). Wear mechanisms of TiN-coated CBN tool during finish hard turning of hot tool die steel. Proceedings of the Institution of Mechanical Engineers, Part B: Journal of Engineering Manufacture, 224(4), 553-566. http://dx.doi.org/10.1243/09544054JEM1664

Elbah, M., Yallese, M. A., Aouici, H., Mabrouki, T., \& Rigal, J. F. (2013). Comparative assessment of wiper and conventional ceramic tools on surface roughness in hard turning AISI 4140 steel. Measurement, 46(9), 30413056.

Fulemova, J., \& Janda, Z. (2014). Influence of the cutting edge radius and the cutting edge preparation on tool life and cutting forces at inserts with wiper geometry. Procedia Engineering, 69, 565-573.

Gaitonde, V. N., Karnik, S. R., Figueira, L., \& Davim, J. P. (2009a). Machinability investigations in hard turning of AISI D2 cold work tool steel with conventional and wiper ceramic inserts. International Journal of Refractory Metals and Hard Materials, 27(4), 754-763.

Gaitonde, V. N., Karnik, S. R., Figueira, L., \& Davim, J. P. (2009b). Analysis of machinability during hard turning of cold work tool steel (type: AISI D2). Materials and Manufacturing Processes, 24(12), 1373-1382.

Gaitonde, V. N., Karnik, S. R., Figueira, L., \& Davim, J. P. (2011). Performance comparison of conventional and wiper ceramic inserts in hard turning through artificial neural network modeling. The International Journal of Advanced Manufacturing Technology, 52(1-4), 101-114.

Grzesik, W. (2009). Wear development on wiper Al 2 O 3-TiC mixed ceramic tools in hard machining of high strength steel. Wear, 266(9), 1021-1028. 
Grzesik, W., \& Wanat, T. (2006). Surface finish generated in hard turning of quenched alloy steel parts using conventional and wiper ceramic inserts. International Journal of Machine Tools and Manufacture, 46(15), 1988-1995.

Guddat, J., M'Saoubi, R., Alm, P., \& Meyer, D. (2011). Hard turning of AISI 52100 using PCBN wiper geometry inserts and the resulting surface integrity. Procedia Engineering, 19, 118-124.

Huang, Y., Chou, Y. K., \& Liang, S. Y. (2007). CBN tool wear in hard turning: a survey on research progresses. The International Journal of Advanced Manufacturing Technology, 35(5-6), 443-453. http://dx.doi.org/10. 1007/s00170-006-0737-6

Özel, T., Karpat, Y., Figueira, L., \& Davim, J. P. (2007). Modelling of surface finish and tool flank wear in turning of AISI D2 steel with ceramic wiper inserts. Journal of materials processing technology, 189(1), 192-198.

Paiva, A. P., Campos, P. H., Ferreira, J. R., Lopes, L. G. D., Paiva, E. J., \& Balestrassi, P. P. (2012). A multivariate robust parameter design approach for optimization of AISI 52100 hardened steel turning with wiper mixed ceramic tool. International Journal of Refractory Metals and Hard Materials, 30(1), 152-163.

Quiza, R., Figueira, L., \& Davim, J. P. (2008). Comparing statistical models and artificial neural networks on predicting the tool wear in hard machining D2 AISI steel. The International Journal of Advanced Manufacturing Technology, 37(7-8), 641-648.

Sahoo, A. K., Baral, A. N., Rout, A. K., \& Routra, B. C. (2012). Multi-objective optimization and predictive modeling of surface roughness and material removal rate in turning using grey relational and regression analysis. Procedia Engineering, 38, 1606-1627. http://dx.doi.org/10.1016/j.proeng.2012.06.197

Sandvik (2014). Turning Tools Manual. Cutting tools from Sandvik coromant (2014).

Srithar, A., Palanikumar, K., \& Durgaprasad, B. (2014). Experimental Investigation and Surface roughness Analysis on Hard turning of AISI D2 Steel using Coated Carbide Insert. Procedia Engineering, 97, 72-77. http://dx.doi.org/10.1016/j.proeng.2014.12.226

Suresh, R., Basavarajappa, S., Gaitonde, V. N., Samuel, G. L., \& Davim, J. P. (2013). State-of-the-art research in machinability of hardened steels. Proceedings of the Institution of Mechanical Engineers, Part B: Journal of Engineering Manufacture, 227(2), 191-209. http://dx.doi.org/10.1177/0954405412464589

\section{Appendix- A Results of Test Experiments}

\begin{tabular}{|c|c|c|c|c|c|c|c|c|c|c|}
\hline \multirow{3}{*}{$\begin{array}{l}\text { Test } \\
\text { No.\# }\end{array}$} & \multirow{3}{*}{$\begin{array}{c}\text { Group } \\
\#\end{array}$} & \multirow{3}{*}{$\begin{array}{l}\text { Speed } \\
\mathrm{M} / \mathrm{min}\end{array}$} & \multirow{3}{*}{$\begin{array}{c}\text { Depth } \\
\text { of cut } \\
\text { mm }\end{array}$} & \multirow{3}{*}{$\begin{array}{c}\text { Feed } \\
\mathrm{mm} / \mathrm{rev}\end{array}$} & \multicolumn{6}{|c|}{ Surface finish $\mu \mathrm{m}$} \\
\hline & & & & & \multicolumn{3}{|c|}{ Wiper insert(A) } & \multicolumn{3}{|c|}{ Conventional insert (B) } \\
\hline & & & & & $\mathrm{R}_{\mathrm{a}}$ & $\mathrm{R}_{\mathrm{t}}$ & $\mathrm{R}_{\mathrm{z}}$ & $\mathrm{R}_{\mathrm{a}}$ & $\mathrm{R}_{\mathrm{t}}$ & $\mathrm{R}_{\mathrm{z}}$ \\
\hline 1 & \multirow[t]{4}{*}{ A1-B1 } & \multirow[t]{4}{*}{75} & \multirow[t]{4}{*}{0.1} & 0.05 & 0.129 & 0.664 & 0.639 & 0.454 & 1.596 & 1.442 \\
\hline 2 & & & & 0.10 & 0.240 & 1.428 & 1.272 & 0.851 & 3.803 & 3.707 \\
\hline 3 & & & & 0.15 & 0.485 & 2.496 & 2.408 & 1.713 & 7.030 & 6.853 \\
\hline 4 & & & & 0.20 & 0.653 & 3.112 & 3.062 & 2.320 & 12.370 & 11.897 \\
\hline 5 & \multirow[t]{4}{*}{ A2-B2 } & \multirow[t]{4}{*}{75} & \multirow[t]{4}{*}{0.15} & 0.05 & 0.191 & 0.987 & 0.934 & 0.663 & 3.045 & 2.900 \\
\hline 6 & & & & 0.10 & 0.245 & 1.425 & 1.355 & 0.858 & 5.335 & 5.243 \\
\hline 7 & & & & 0.15 & 0.488 & 2.105 & 2.031 & 1.704 & 7.890 & 7.809 \\
\hline 8 & & & & 0.20 & 0.652 & 3.095 & 2.961 & 2.280 & 11.795 & 11.685 \\
\hline 9 & \multirow[t]{4}{*}{ A3-B3 } & \multirow[t]{4}{*}{75} & \multirow[t]{4}{*}{0.20} & 0.05 & 0.199 & 0.808 & 0.695 & 0.696 & 1.867 & 1.739 \\
\hline 10 & & & & 0.10 & 0.387 & 1.308 & 1.118 & 1.349 & 4.839 & 4.731 \\
\hline 11 & & & & 0.15 & 0.489 & 1.719 & 1.675 & 1.714 & 7.775 & 7.628 \\
\hline 12 & & & & 0.20 & 0.656 & 2.932 & 2.800 & 2.303 & 12.637 & 12.534 \\
\hline
\end{tabular}




\begin{tabular}{|c|c|c|c|c|c|c|c|c|c|c|}
\hline 13 & \multirow[t]{4}{*}{ A4-B4 } & \multirow[t]{4}{*}{75} & \multirow[t]{4}{*}{0.25} & 0.05 & 0.205 & 1.157 & 1.093 & 0.715 & 3.536 & 3.433 \\
\hline 14 & & & & 0.10 & 0.398 & 1.504 & 1.424 & 1.388 & 4.912 & 4.778 \\
\hline 15 & & & & 0.15 & 0.519 & 2.469 & 2.393 & 1.814 & 8.340 & 7.163 \\
\hline 16 & & & & 0.20 & 0.687 & 3.193 & 3.068 & 2.402 & 13.153 & 13.058 \\
\hline 17 & \multirow[t]{4}{*}{ A5-B5 } & \multirow[t]{4}{*}{100} & \multirow[t]{4}{*}{0.1} & 0.05 & 0.235 & 1.114 & 1.053 & 0.746 & 3.621 & 3.477 \\
\hline 18 & & & & 0.10 & 0.309 & 2.191 & 1.926 & 0.938 & 5.314 & 5.251 \\
\hline 19 & & & & 0.15 & 0.490 & 2.804 & 2.588 & 1.521 & 8.655 & 8.465 \\
\hline 20 & & & & 0.20 & 0.612 & 3.068 & 2.972 & 1.862 & 12.145 & 12.045 \\
\hline 21 & \multirow[t]{4}{*}{ A6-B6 } & \multirow[t]{4}{*}{100} & \multirow[t]{4}{*}{0.15} & 0.05 & 0.248 & 1.206 & 1.151 & 0.780 & 3.629 & 3.521 \\
\hline 22 & & & & 0.10 & 0.351 & 2.060 & 1.969 & 1.094 & 5.519 & 5.335 \\
\hline 23 & & & & 0.15 & 0.504 & 2.828 & 2.688 & 1.577 & 8.844 & 8.540 \\
\hline 24 & & & & 0.20 & 0.637 & 3.403 & 3.211 & 1.989 & 12.117 & 12.000 \\
\hline 25 & \multirow[t]{4}{*}{ A7-B7 } & \multirow[t]{4}{*}{100} & \multirow[t]{4}{*}{0.20} & 0.05 & 0.248 & 1.384 & 1.263 & 0.752 & 3.484 & 3.328 \\
\hline 26 & & & & 0.10 & 0.381 & 2.126 & 1.972 & 1.165 & 5.370 & 5.242 \\
\hline 27 & & & & 0.15 & 0.557 & 3.070 & 2.795 & 1.695 & 9.053 & 8.491 \\
\hline 28 & & & & 0.20 & 0.645 & 3.294 & 3.063 & 1.964 & 12.004 & 11.716 \\
\hline 29 & \multirow[t]{4}{*}{ A8-B8 } & \multirow[t]{4}{*}{100} & \multirow[t]{4}{*}{0.25} & 0.05 & 0.268 & 1.906 & 1.777 & 0.827 & 3.074 & 2.904 \\
\hline 30 & & & & 0.10 & 0.423 & 2.516 & 2.258 & 1.279 & 5.170 & 4.952 \\
\hline 31 & & & & 0.15 & 0.563 & 3.655 & 3.531 & 1.704 & 8.234 & 8.057 \\
\hline 32 & & & & 0.20 & 0.660 & 3.544 & 3.409 & 1.990 & 10.921 & 10.638 \\
\hline 33 & \multirow[t]{4}{*}{ A9-B9 } & \multirow[t]{4}{*}{125} & \multirow[t]{4}{*}{0.1} & 0.05 & 0.326 & 2.732 & 2.173 & 0.817 & 2.922 & 2.684 \\
\hline 34 & & & & 0.10 & 0.524 & 3.722 & 3.588 & 1.331 & 4.958 & 4.696 \\
\hline 35 & & & & 0.15 & 0.608 & 3.616 & 3.508 & 1.558 & 8.552 & 8.257 \\
\hline 36 & & & & 0.20 & 0.652 & 3.907 & 3.705 & 1.654 & 11.345 & 11.063 \\
\hline 37 & \multirow[t]{4}{*}{ A10-B10 } & \multirow[t]{4}{*}{125} & \multirow[t]{4}{*}{0.15} & 0.05 & 0.338 & 2.957 & 2.484 & 0.852 & 3.046 & 2.828 \\
\hline 38 & & & & 0.10 & 0.553 & 4.257 & 3.767 & 1.377 & 4.894 & 4.751 \\
\hline 39 & & & & 0.15 & 0.615 & 3.647 & 3.503 & 1.544 & 8.033 & 7.924 \\
\hline 40 & & & & 0.20 & 0.737 & 4.033 & 3.876 & 1.827 & 11.479 & 11.218 \\
\hline 41 & \multirow[t]{4}{*}{ A11-B11 } & \multirow[t]{4}{*}{125} & \multirow[t]{4}{*}{0.20} & 0.05 & 0.345 & 2.696 & 2.239 & 0.867 & 2.760 & 2.644 \\
\hline 42 & & & & 0.10 & 0.567 & 3.574 & 3.132 & 1.451 & 4.642 & 4.504 \\
\hline 43 & & & & 0.15 & 0.646 & 3.941 & 3.617 & 1.629 & 7.744 & 7.468 \\
\hline 44 & & & & 0.20 & 0.752 & 4.269 & 3.585 & 1.877 & 11.218 & 10.764 \\
\hline 45 & A12-B12 & 125 & 0.25 & 0.05 & 0.349 & 2.804 & 2.467 & 0.873 & 2.913 & 2.641 \\
\hline
\end{tabular}




\begin{tabular}{|c|c|c|c|c|c|c|c|c|c|c|}
\hline 46 & & & & 0.10 & 0.580 & 3.563 & 2.819 & 1.451 & 5.091 & 4.778 \\
\hline 47 & & & & 0.15 & 0.652 & 3.396 & 3.124 & 1.631 & 7.977 & 7.741 \\
\hline 48 & & & & 0.20 & 0.786 & 4.199 & 4.036 & 1.960 & 10.100 & 9.930 \\
\hline 49 & \multirow[t]{4}{*}{ A13-B13 } & \multirow[t]{4}{*}{150} & \multirow[t]{4}{*}{0.1} & 0.05 & 0.311 & 2.658 & 2.442 & 0.629 & 2.499 & 2.306 \\
\hline 50 & & & & 0.10 & 0.356 & 3.038 & 2.548 & 0.716 & 5.706 & 5.294 \\
\hline 51 & & & & 0.15 & 0.672 & 3.941 & 3.649 & 1.348 & 7.184 & 6.926 \\
\hline 52 & & & & 0.20 & 0.688 & 3.561 & 3.308 & 1.384 & 10.824 & 10.565 \\
\hline 53 & \multirow[t]{4}{*}{ A14-B14 } & \multirow[t]{4}{*}{150} & \multirow[t]{4}{*}{0.15} & 0.05 & 0.333 & 2.840 & 2.386 & 0.678 & 2.432 & 2.280 \\
\hline 54 & & & & 0.10 & 0.391 & 3.425 & 2.945 & 0.785 & 5.418 & 5.243 \\
\hline 55 & & & & 0.15 & 0.782 & 4.045 & 3.847 & 1.581 & 7.387 & 7.088 \\
\hline 56 & & & & 0.20 & 0.788 & 3.266 & 3.157 & 1.645 & 11.191 & 10.846 \\
\hline 57 & \multirow[t]{4}{*}{ A15-B15 } & \multirow[t]{4}{*}{150} & \multirow[t]{4}{*}{0.20} & 0.05 & 0.380 & 3.038 & 2.644 & 0.783 & 2.142 & 2.066 \\
\hline 58 & & & & 0.10 & 0.388 & 3.664 & 2.925 & 0.802 & 4.573 & 4.309 \\
\hline 59 & & & & 0.15 & 0.619 & 4.161 & 3.570 & 1.253 & 7.057 & 6.722 \\
\hline 60 & & & & 0.20 & 0.709 & 3.466 & 3.156 & 1.474 & 10.960 & 10.628 \\
\hline 61 & \multirow[t]{4}{*}{ A16-B16 } & \multirow[t]{4}{*}{150} & \multirow[t]{4}{*}{0.25} & 0.05 & 0.429 & 3.666 & 2.938 & 0.864 & 2.074 & 1.878 \\
\hline 62 & & & & 0.10 & 0.447 & 3.687 & 3.275 & 0.956 & 3.909 & 3.794 \\
\hline 63 & & & & 0.15 & 0.676 & 3.116 & 2.889 & 1.361 & 7.299 & 7.018 \\
\hline 64 & & & & 0.20 & 0.733 & 4.163 & 3.909 & 1.475 & 11.189 & 10.766 \\
\hline
\end{tabular}

\section{Copyrights}

Copyright for this article is retained by the author(s), with first publication rights granted to the journal.

This is an open-access article distributed under the terms and conditions of the Creative Commons Attribution license (http://creativecommons.org/licenses/by/3.0/). 